\title{
Peculiar Set-Retarding Effect of Miserly Amounts of Pyrocatechol on Calcium Aluminate Cement Hydration
}

\author{
Alexey Brykov¹, Mikhail Voronkov¹, Olga Nekrasova', Maxim Mokeev² \\ ${ }^{1}$ Department of Chemistry of Substances and Materials, Saint-Petersburg State Institute of Technology, St. Petersburg, Russia \\ ${ }^{2}$ Institute of Macromolecular Compounds, St. Petersburg, Russia \\ Email: brykov@yahoo.com
}

How to cite this paper: Brykov, A., Voronkov, M., Nekrasova, O. and Mokeev, M. (2018) Peculiar Set-Retarding Effect of Miserly Amounts of Pyrocatechol on Calcium Aluminate Cement Hydration. Materials Sciences and Applications, 9, 455-463. https://doi.org/10.4236/msa.2018.95031

Received: April 6, 2018

Accepted: May 13, 2018

Published: May 17, 2018

Copyright $\odot 2018$ by authors and Scientific Research Publishing Inc. This work is licensed under the Creative Commons Attribution International License (CC BY 4.0).

http://creativecommons.org/licenses/by/4.0/

\begin{abstract}
Pyrocatechol (benzene-1,2-diol) acts upon a calcium aluminate cement (CAC) as a very strong set and hardening retardant and a potent plasticizing agent at the same time. By studying CAC-pyrocatechol compositions using different analytical methods it was shown that pyrocatechol indeed slows CAC hydration and decreases strength of hardening stone. What makes this behavior a peculiar one is that pyrocatechol is known to accelerate Portland cement (PC) setting drastically.
\end{abstract}

\section{Keywords}

Pyrocatechol, Calcium Aluminate Cements, Hydration, NMR Spectroscopy

\section{Introduction}

Pyrocatechol (benzene-1,2-diol) has been reported to decrease Portland cement (PC) setting time significantly even when very small amounts of the substance was admixed [1]. In [2] an ${ }^{27} \mathrm{Al}$ NMR spectroscopy disclosed this accelerating effect is due to a rapid ettringite formation by reaction between $\mathrm{C}_{3} \mathrm{~A}$ and gypsum, and that pyrocatechol has no noticeable effect on calcium silicates hydration (as shown by ${ }^{29} \mathrm{Si}$ NMR spectroscopy). The primary factor that determines this acceleration effect is likely being an interaction between aluminum ions and pyrocatechol that results in chelate complex formation. Allowing for this theory, it's intriguing to study how this particular phenol affects calcium aluminate cements (CAC) setting and hydration considering regular CAC primarily consists of $\mathrm{CaO} \cdot \mathrm{Al}_{2} \mathrm{O}_{3}$ and contains other calcium aluminates as well. When looked through dozens of publications this subject seems almost completely missed out. 
The present work focuses mainly on pyrocatechol influence on CAC setting time, cement paste consistency and compressive strength of a cured cement paste, as well as how exactly pyrocatechol affects calcium aluminates hydration. We also attempt to describe and explain obtained results in correlation to known theories of CAC hydration.

\section{Experimental Part}

Aluminate cements used in this study are Secar 38R, Cement Fondu and Ternal EV (Kerneos, France). The XRD patterns of the dry cements are shown in Figure 1. The main phase of Secar 38R and Cement Fondu is monocalcium aluminate

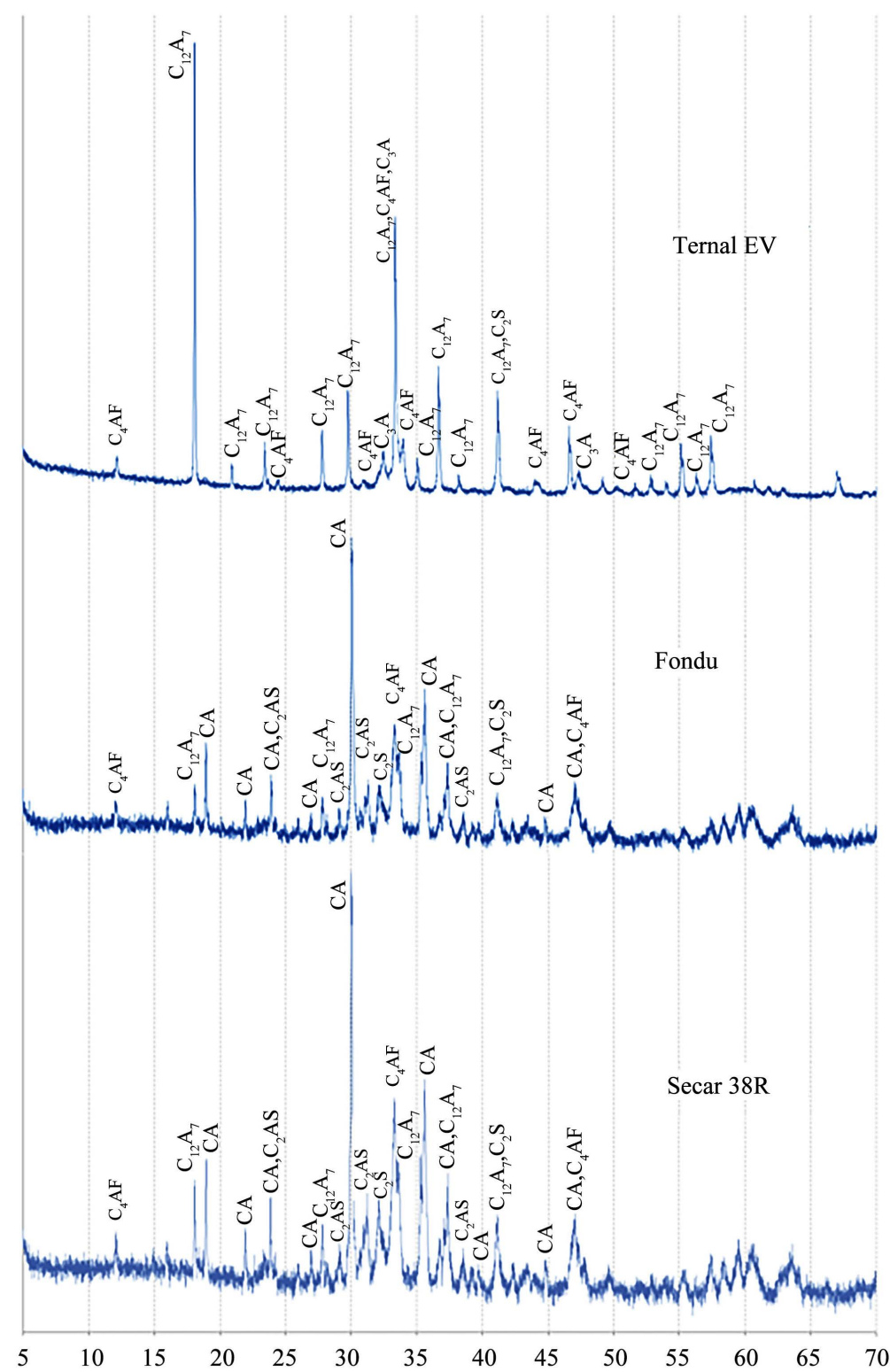

Figure 1. XRD patterns of Secar 38R, cement Fondu and Ternal EV with peaks identified (Rigaku SmartLab 3 X-ray diffractometer, BB, Cu K-alpha, $\left.5^{\circ} 2 \theta / \mathrm{s}\right)$. Along $\mathrm{X}$ is ${ }^{\circ} 2 \theta$. 
(CA) with other phases also present, such as $\mathrm{C}_{12} \mathrm{~A}_{7}, \mathrm{C}_{4} \mathrm{AF}, \mathrm{C}_{2} \mathrm{~S}, \mathrm{C}_{2} \mathrm{AS}$. In case of Ternal EV (taken for comparison purposes), $\mathrm{C}_{12} \mathrm{~A}_{7}$ is a predominant phase; some amount of $\mathrm{C}_{3} \mathrm{~A}$ and $\mathrm{C}_{4} \mathrm{AF}$ are present; the content of $\mathrm{CA}$ is inferior if at all.

Pyrocatechol was purified through evaporation and condensation (melting point $98^{\circ} \mathrm{C}-104^{\circ} \mathrm{C} ; 104^{\circ} \mathrm{C}$ - lit.) and appears as colorless thin plates.

Water to cement ratio $(\mathrm{w} / \mathrm{c})$ in case of Secar $38 \mathrm{R}$ was 0.26 , which refer to standard consistency of cement paste determined by GOST 310.3-76 (Vicat plunger penetrates to $5-7 \mathrm{~mm}$ from the bottom of the Vicat mold). In case of Cement Fondu and Ternal EV, the values of w/c were 0.265 and 0.21 , referring to standard consistency of those cements, correspondingly. Pyrocatechol in amounts corresponding to $(0.002-0.01) \%$ by weight of CAC was dissolved in distilled water destined for mixing of cement.

To measure flow of cement paste a small cone of approx. $55 \times 38 \times 30 \mathrm{~mm}$ was used. The cone placed on a flow table was filled with cement paste (100 g), then the cone gets removed and the sample shaken 15 times.

Setting time of cement paste was determined using Vicat apparatus by GOST 310.3-76.

To evaluate the effect of pyrocatechol on cement paste hardening a compressive strength of $30 \times 30 \times 30 \mathrm{~mm}$ samples was measured. Samples were stored at $20^{\circ} \mathrm{C}, 95 \% \mathrm{RH}$ (normal conditions) for 24 hours, and then stored under water until the moment of measurement.

An early hydration of CAC Secar 38R with pyrocatechol admixture was studied by means of IR spectroscopy and ${ }^{27} \mathrm{Al}$ solid-state NMR spectroscopy. For this purposes a small amount of CAC paste with $0.01 \%$ of pyrocatechol was prepared by mixing the cement with water thoroughly. After 4 hours of storage under normal conditions a bit of sample (few grams) was powdered in mortar in an excess of acetone to remove any residue water and the sludge was vacuum filtered through a glass filter. The solid residue was then washed with acetone two more times and dried on glass filter. Dried sample had been stored in sealed container at $-18^{\circ} \mathrm{C}$ until the moment of measurements. A reference sample of pure hydrated CAC paste was prepared and handled the same way.

IR spectra were obtained using FTIR ATR spectroscopy (Shimadzu IRTracer-100 FTIR Spectrophotometer with ATR accessory). High-resolution NMR spectra acquired on Bruker AVANCE II-500WB spectrometer. NMR spectra recorded at $130.32 \mathrm{MHz}$ by single-pulse excitation, the pulse duration of $0.7 \mu \mathrm{s}$ $(\pi / 12)$ with a delay of $0.5 \mathrm{sec}$, a number of scans was 2048 . The samples' material (approx. $100 \mathrm{mg}$ ) were packed in zirconia rotors (D $4 \mathrm{~mm}$ ) and rotated at 13 $\mathrm{kHz}$. Chemical shifts are given in ppm relative to $\mathrm{AlCl}_{3} \cdot 6 \mathrm{H}_{2} \mathrm{O}$. An assignment of the signals is accomplished in accordance with published data [3] [4].

\section{Results and Discussion}

Physical and mechanical properties of Secar 38R cement paste with pyrocatechol admixture are shown in Table 1 . It's clearly seen that pyrocatechol slows CAC 
setting dramatically with this effect more pronounced the more pyrocatechol is introduced. When introduced in larger amounts it also induces a strong plasticizing effect on cement paste and decreases strength of cement stone compared to reference samples. The retarding effect is observed also for Cement Fondu characterized by similar phase combination (Table 2).

In Figure 2 there are shown IR spectra of dry cement Secar 38R and cement pastes (both reference and with $0.01 \mathrm{wt} \%$ of pyrocatechol) at the point of 4 hours since water addition.

After 4 hours of hydration some noticeable changes take place in reference sample paste composition: an intensity of a signal at $800 \mathrm{~cm}^{-1}$, which refer to 4-coordinated aluminum ions of dry calcium aluminates [3] decreases, while signals of $\mathrm{OH}^{-}$oscillation in hydration products at 1400 and $3400 \mathrm{~cm}^{-1}$ are quite distinct. At the same time, for pyrocatechol containing paste there's no difference from dry cement spectrum which indicates that no hydration began yet.

This observation is also confirmed with ${ }^{27} \mathrm{Al} \mathrm{NMR} \mathrm{spectra} \mathrm{(Figure} \mathrm{3):} \mathrm{a} \mathrm{strong}$ peak at $80 \mathrm{ppm}$ corresponds to $\mathrm{AlO}_{4}$ tetrahedra of aluminate phases of CAC (CA и $\mathrm{C}_{12} \mathrm{~A}_{7}$ ) [4]. At $10 \mathrm{ppm}$ there's a weak signal that can be referred to aluminum-oxygen octahedra of $\mathrm{C}_{4} \mathrm{AF}$ and $\mathrm{C}_{2} \mathrm{AS}$ phases or it could also belong to hydrated cement as it absorbs air moisture.

Table 1. Properties of cement pastes of Secar 38R with pyrocatechol.

\begin{tabular}{|c|c|c|c|c|}
\hline \multirow[b]{2}{*}{ Property } & \multicolumn{4}{|c|}{ Pyrocatechol amount by weight of cement, \% } \\
\hline & $\begin{array}{c}0.000 \\
\text { (reference) }\end{array}$ & 0.002 & 0.005 & 0.010 \\
\hline \multicolumn{5}{|c|}{ Setting time, min: } \\
\hline initial & 45 & 50 & 240 & over $9 \mathrm{~h}$ \\
\hline final & 165 & 260 & 580 & - \\
\hline Flow, mm & 55 & 56 & 100 & 100 \\
\hline \multicolumn{5}{|c|}{ Compressive strength $(\mathrm{MPa})$ at day: } \\
\hline 1 & 54.3 & 54.5 & 41.7 & 1.7 \\
\hline 3 & 65.0 & - & 51.6 & - \\
\hline 7 & 65.7 & 58.3 & 49.1 & - \\
\hline
\end{tabular}

Table 2. Properties of cement pastes of other CACs with pyrocatechol.

\begin{tabular}{|c|c|c|c|c|c|c|}
\hline \multirow{3}{*}{ Property } & \multicolumn{3}{|c|}{ Cement Fondu } & \multicolumn{3}{|c|}{ Ternal EV } \\
\hline & \multicolumn{6}{|c|}{ Pyrocatechol amount by weight of cement, \% } \\
\hline & $\begin{array}{c}0.000 \\
\text { (reference) }\end{array}$ & 0.005 & 0.010 & $\begin{array}{c}0.000 \\
\text { (reference) }\end{array}$ & 0.005 & 0.010 \\
\hline \multicolumn{7}{|c|}{ Setting time, min: } \\
\hline initial & 85 & 85 & over $8 \mathrm{~h}$ & 40 & 40 & 60 \\
\hline final & 240 & over $8 \mathrm{~h}$ & over $20 \mathrm{~h}$ & 120 & 70 & 100 \\
\hline Flow, mm & 64 & 64 & 123 & 182 & 195 & 202 \\
\hline
\end{tabular}




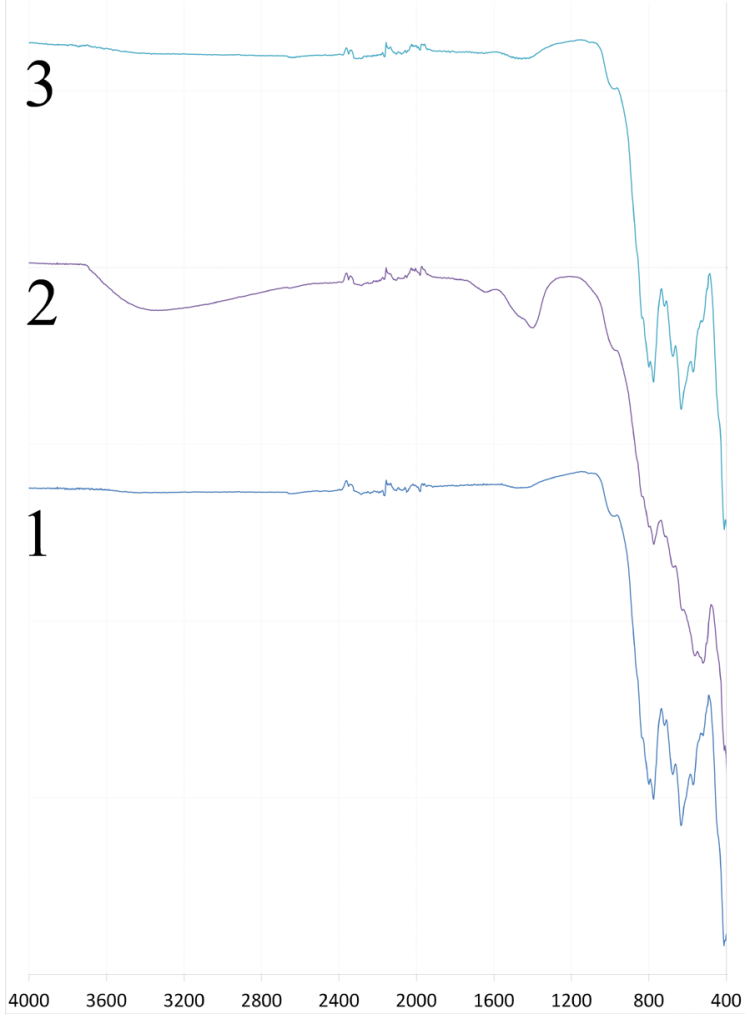

Figure 2. IR reflection spectra of dry Secar 38R cement (1); reference cement paste (2) and paste with $0.01 \%$ of pyrocatechol (3) at 4 hours of hydration. Along $\mathrm{X}$ is a wavenumber $(\mathrm{k}), \mathrm{cm}^{-1}$. Along $\mathrm{Y}$ is absorbance.

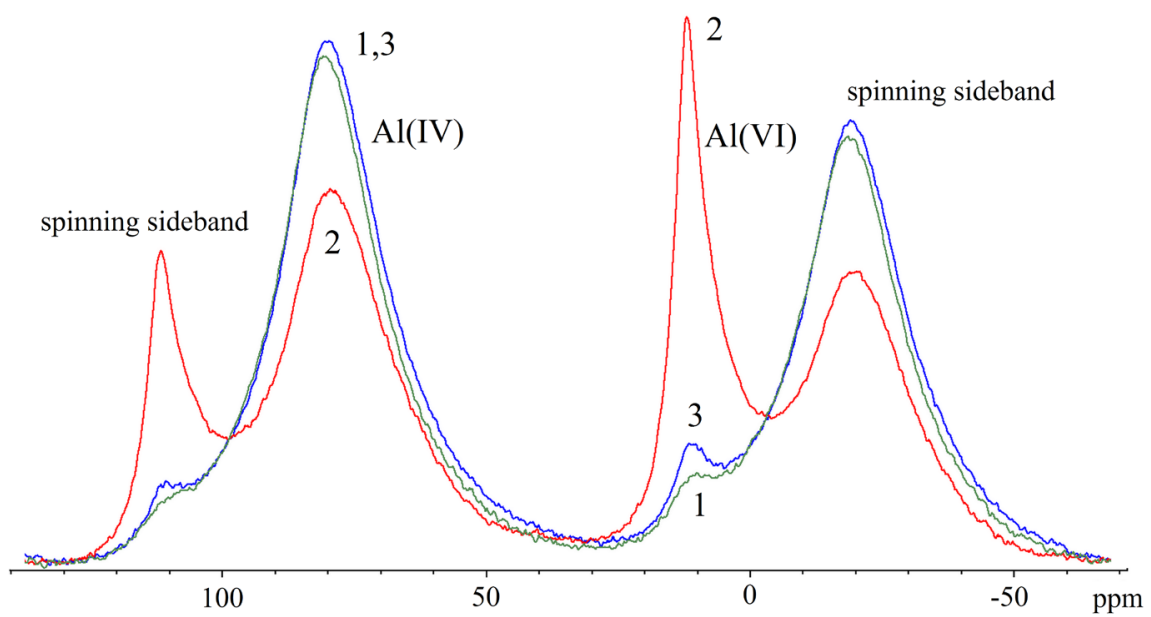

Figure $3 .{ }^{27} \mathrm{Al} \mathrm{NMR}$ spectra of dry cement Secar 38R (1); reference cement paste (2) and paste with $0.01 \%$ of pyrocatechol (3) at 4 hours of hydration. Along $\mathrm{X}$ is a chemical shift $(\delta)$, ppm. Along $\mathrm{Y}$ is relative intensity.

At 4 hours from the moment of water addition a reference paste has fully set, meanwhile for pyrocatechol containing sample it hasn't even started. Strong differences between spectra of those two can be observed: for reference paste calcium aluminate phases' signal diminishes and a strong peak of hydrates arises at 
$10 \mathrm{ppm}$, when pyrocatechol stops cement hydration almost completely. Comparing integral intensities of signals at $80 \mathrm{ppm}$ allows for approximate quantitative estimation of hydration rate for both cases, which results in $23 \%$ for reference and about $1 \%$ of pyrocatechol sample.

Summarizing results of mechanical properties evaluation and spectroscopic analyses it may be concluded the pyrocatechol suppresses hydration of CAC, its setting and hardening and while this effect is not something completely surprising (considering many organic compounds, in particular $\alpha$-hydroxy carboxylic acids, carbohydrates and so on behave the same way) there are two features that takes pyrocatechol aside. First, it influences Portland cement and calcium aluminate cement in very different ways: accelerating the setting of the former [2] and slowing for the latter. Secondly, these effects become noticeable at miniscule dosages of pyrocatechol-some hundredths and thousandths of a percent by weight of cement. Widely known and used in practice organic modifiers of setting time usually affects both PC and CAC in the same manner and their dosages typically lay in range of tenths of a percent (see, for example, [5]).

To qualitatively study how various components of PC reacts with water in the presence of pyrocatechol, additional experiments was carried out using several materials: an industrial grade Portland cement clinker (phase composition, wt\%: $\mathrm{C}_{3} \mathrm{~S}$ 54-57, $\mathrm{C}_{2} \mathrm{~S}$ 19-21, $\mathrm{C}_{3} \mathrm{~A}+\mathrm{C}_{4} \mathrm{AF} 24-25$ - petrographic examination), synthetic $\mathrm{C}_{3} \mathrm{~A}$ and $\mathrm{C}_{4} \mathrm{AF}$ minerals and a calcined gypsum ( $\beta$-calcium sulfate hemihydrate). These materials in finely powdered form were mixed with distilled water (as reference samples) at a ratio of $0.4\left(0.5\right.$ for $\left.\mathrm{CaSO}_{4} \cdot 0.5 \mathrm{H}_{2} \mathrm{O}\right)$ and with water solution of pyrocatechol $(0.02 \mathrm{wt} \%$ by the weight of dry powder) then reaction results were examined organoleptically. Several observations were made: in comparison to reference samples pyrocatechol 1) exerts a strong plasticizing effect upon gypsum paste, 2) leads to a very strong exothermic effect and an instantaneous set of $\mathrm{C}_{3} \mathrm{~A}, 3$ ) has no influence on $\mathrm{C}_{4} \mathrm{AF}$ hydration, 4) accelerates PC clinker set and heat release as well.

All the above mentioned allows for the conclusion that the quickened set of PC with pyrocatechol admixed is mainly due to its influence on $\mathrm{C}_{3} \mathrm{~A}$ phase hydration kinetic, which agrees well with our previous research results [2]. Hence the pyrocatechol is expected to have an essentially different impact on hydration of tricalcium aluminate of PC and those aluminates of CAC, such as CA, which are of less basicity.

To give a comprehensive explanation of this phenomenon is quite difficult considering an actual mechanism of dissolving of calcium aluminates isn't worked out yet and it's still debated be it congruent or incongruent [5] [6] [7] [8]. Based on available data on early period of hydration of different aluminate phases we can only make some assumptions about those effects.

When first come into contact with water, $\mathrm{C}_{3} \mathrm{~A}$ particle surface is overgrown with hydration products which limit its further reactivity (both with presence of gypsum or without it) for at least some period of time [7] [8]; for the duration of the period a high hydraulic activity of $\mathrm{C}_{3} \mathrm{~A}$ is extinguished. This thin layer of 
products is proposed to consist of unstable hexagonal phases, which then converse into stable state. This process increases permeability of the layer so the hydration goes on and heat is been released [6] [8]. Hence such compounds that stabilize initial layer slows the hydration and vice versa [6] [7], e.g. triethanolamine (TEA) is known to promote $\mathrm{C}_{3} \mathrm{~A}$ reaction with water [8].

Decrease in hydration rate of $\mathrm{C}_{3} \mathrm{~A}$ can also be induced by formation of amorphous hydrated aluminum hydroxide layer covering the grain (perhaps, due to incongruent dissolving of $\mathrm{C}_{3} \mathrm{~A}$ ). Its potency to screen the grain of $\mathrm{C}_{3} \mathrm{~A}$ from water depends on many factors, including composition of liquid phase [5] [6] [7]. Followed by layer destruction in which $\mathrm{Ca}^{2+}$ and $\mathrm{OH}^{-}$ions from liquid phase also participate, $\mathrm{C}_{3} \mathrm{~A}$ hydration eventually resumes.

In presence of gypsum some amorphous layer of $\mathrm{Ca}^{2+}$ and $\mathrm{SO}_{4}^{2-}$ stabilized product is formed on surface first, which slows hydration and initiate the induction period, and only then from this primal product ettringite crystals start to grow [7]. This way a typical PC hydration rate and setting rate are controlled predominantly by $\mathrm{Ca}(\mathrm{OH})_{2}$ and C-S-H nuclei formation [5]. Consequently, as $\mathrm{Ca}^{2+}$ and $\mathrm{SO}_{4}^{2-}$ in liquid phase exhaust, the layer becomes unstable and permeable so $\mathrm{C}_{3} \mathrm{~A}$ surface is not restricted from water access anymore.

On the other hand, if excess ettringite formation is promoted somehow in " $\mathrm{C}_{3} \mathrm{~A}+$ gypsum" system it may shorter the induction period and expedite cement setting. In practical applications this effect is usually achieved by introducing either some aluminum containing compounds that readily react with gypsum themselves to form an ettringite [9] or other additives to induce the reaction between PC own phases and gypsum-one example of the latter is pyrocatechol [2].

Pyrocatechol is a chelating agent that binds calcium and aluminum ions into strong water-soluble complexes. This interaction seems to affects primal layer of hydrates that inhibit $\mathrm{C}_{3} \mathrm{~A}$ or perhaps the layer formation is cancelled in pyrocatechol presence, so $\mathrm{C}_{3} \mathrm{~A}$ is unleashed to react with water whether gypsum is available or not. TEA is known to possess similar properties, so its action can be explained using similar approach.

Calcium aluminate (CA) - a main constituent of CACs with moderate $\mathrm{Al}_{2} \mathrm{O}_{3}$ content-reacts with water via through-solution mechanism [7], first proposed by Le Chatelier and confirmed by numerous researches thereafter [5], although there still appears a layer of aluminum-rich hydrated product when CA phase makes contact with water [7]. CA likely undergoes congruent dissolution, this leads to supersaturation of solution by $\mathrm{AH}_{3}$ and hydrated calcium aluminates and create favorable conditions for crystallization nuclei to emerge and grow. In this case, the duration of induction period is determined by the time it takes these nuclei to become stabile and start growing. By the end of induction period setting occurs. $\mathrm{C}_{12} \mathrm{~A}_{7}$ phase, if presented, dissolves readily and quickly supersaturate the solution with respect to $\mathrm{C}_{2} \mathrm{AH}_{8}$ so nucleation rate increases considerably [7].

In those cements where CA predominate, pyrocatechol may act as "poison- 
ing" agent to inhibit nuclei formation by capturing calcium and aluminum ions from solution into strong complexes. In this regard, pyrocatechol behave as a typical retardant, however the retarding effect is pronounced even when miniscule amounts of pyrocatechol are introduced, and what we call a miniscule is actually an order or two below dosages of widespread retardant agents used in practice nowadays.

In view of all this, a specific note should be made about Ternal EV behavior. Composed principally of $\mathrm{C}_{12} \mathrm{~A}_{7}$, that "stands between" $\mathrm{C}_{3} \mathrm{~A}$ and $\mathrm{CA}$ on $\mathrm{CaO}-\mathrm{Al}_{2} \mathrm{O}_{3}$ phase diagram, and some amount of $\mathrm{C}_{3} \mathrm{~A}$ (as is identified by XRD) and traces of CA (if any), this cement shows no clear behavior when exposed to pyrocatechol, at least for dosages tried in this work (Table 2).

\section{Conclusions}

As it was disclosed by spectral analysis and mechanical properties evaluation tests, the pyrocatechol inhibits hydration of calcium aluminates of CAC, which in turn affects setting time of cement paste and its compressive strength development. At the same time, pyrocatechol accelerates Portland cement hydration by promoting $\mathrm{C}_{3} \mathrm{~A}$ reaction with water and gypsum and inducing ettringite formation $\left(\mathrm{C}_{3} \mathrm{~A}+3 \mathrm{CaSO}_{4} \cdot 2 \mathrm{H}_{2} \mathrm{O}+26 \mathrm{H}_{2} \mathrm{O} \rightarrow \mathrm{C}_{3} \mathrm{~A} \cdot 3 \mathrm{CaSO}_{4} \cdot 32 \mathrm{H}_{2} \mathrm{O}\right)$.

Set-retarding effect of pyrocatechol is exhibited at miserly dosages, some 0.002 $0.005 \%$ proportional to calcium aluminate cement weight. The pyrocatechol binds calcium and aluminum ions into strong chelate complexes and thus inhibits nuclei formation and developing.

\section{References}

[1] Justnes, H. (2010) Acceleration by Retardation in Hydration Process for Cement-Based Materials. The Journal of the Chinese Ceramic Society, 38, 1618-1622.

[2] Brykov, A.S., Paritskaya, N.S. and Mokeev M.V. (2016) Effect of Pyrocatechol on Hydration of Portland Cement in the Early Period. Zement i Ego Primenenie ( $\mathrm{Ce}$ ment and Its Application), 6, 80-82.

[3] Fernández-Carrasco, L., Torrens-Martín, D., Morales, L.M. and Martínez-Ramírez, S. (2012). Infrared Spectroscopy in the Analysis of Building and Construction Materials, Infrared Spectroscopy - Materials Science, Engineering and Technology. In: Theophanides, T., Ed., Infrared Spectroscopy - Materials Science, Engineering and Technology, InTech, 369-382.

https://mts.intechopen.com/books/infrared-spectroscopy-materials-science-enginee ring-and-technology/infrared-spectroscopy-of-cementitious-materials

[4] Cong, X. and Kirkpatrick, R.J. (1993) Hydration of Calcium Aluminate Cements: A Solid-State ${ }^{27} \mathrm{Al}$ NMR Study. Journal of the American Ceramic Society, 76, 409-416. https://doi.org/10.1111/j.1151-2916.1993.tb03799.x

[5] Taylor, H. (1997) Cement Chemistry. 2nd Edition, Thomas Telford, London. https://doi.org/10.1680/cc.25929

[6] Gartner, E.M., Young, J.F., Damidot, D.A. and Jawed, I. (2008) Hydration of Portland cement. In: Gartner, P. and Bensted, J., Eds., Structure and Performance of Cements, Taylor \& Francis Group, London, 107-113. 
[7] Kurdowski, W. (2014) Cement and Concrete Chemistry. Springer, Dordrecht. https://doi.org/10.1007/978-94-007-7945-7

[8] Odler, I. (2003) Hydration, Setting and Hardening of Portland Cement. In: Hewlett, P., Ed., Lea's Chemistry of Cement and Concrete, 4th Edition, Elsevier Science \& Technology Books, 241-297.

[9] Myrdal, R. (2007) Accelerating Admixtures for Concrete. State of the Art: SINTEF Report N SBF BK A07025, Trondheim. 